Eventos 



\title{
A VIVÊNCIA DA GRAVIDEZ EM MULHERES CARDIOPATAS ${ }^{\star}$
}

\author{
Natalia Pinho de Oliveira Ribeiro; \\ Alexandre Rafael de Mello Schier; \\ Bruno Strey Vilela $\star \star$ \\ Adriana Cardoso O. Silva $a^{\star \star}$
}

\section{Palavras-chave: Psicologia Hospitalar; Cardiologia; Obstetrícia.}

Fundamentação teórica: Observamos o crescimento no número de trabalhos voltados para os aspectos psicológicos de pacientes cardiopatas, no entanto, ainda mostram-se escassos os estudos referentes às vivências de mulheres que apresentam cardiopatias, durante o período gestacional. Objetivos: Esse estudo visa investigar como se dá a interposição da gravidez na vida de mulheres cardiopatas, acompanhando suas novas rotinas e o quanto este momento interfere em suas vidas. O foco do estudo está na percepção das próprias gestantes sobre suas vivências. Delineamento: Estudo observacional transversal qualitativo. População e métodos: Entrevista semi-estruturada, realizada com mulheres cardiopatas grávidas. Resultados: Entre as questões que mais preocupam essas mulheres estão a possibilidade de má formação fetal, principalmente devido aos remédios utilizados durante a gravidez, e a falta de movimentação do feto, tendo essa última aparecido no discurso de todas as participantes. Todas relataram que seus temores persistiam mesmo após saberem, por meio da equipe de saúde, que estava tudo bem com o feto. As preocupações geram grandes sentimentos de angústia e fazem com que as gestantes tenham dificuldades para dormir devido aos pensamentos invasivos relacionados a possíveis problemas na gravidez. O aumento de peso também se mostrou uma preocupação entre elas, assim como a presença de varizes e sangramentos, que acabam, segundo as próprias gestantes, diminuindo a auto-estima e afetando seus cotidianos. O temor de um possível aborto, permeado pela possibilidade de complicação real, também é uma constante, sendo que uma das entrevistadas já havia sofrido três abortos antes da gravidez atual. Outra queixa presente se relaciona com a proibição, pela equipe médica, da pratica de exercícios físicos, por serem elas consideradas "grávidas de risco". Conclusão: O período gravídico já é tido como um momento de crise na vida da mulher devido às diversas mudanças impostas por ele. No caso da gestante que apresenta problemas cardíacos prévios, outras tensões são adicionadas ao processo, algumas imaginárias, outras com base no real, o que torna esse momento ainda mais delicado para elas.

\footnotetext{
$\star$ Trabalho apresentado no $26^{\circ}$ Congresso de Cardiologia da SOCERJ - 24 a 27 de junho de 2009.

$\star \star$ Graduandos em Psicologia pela Universidade Federal Fluminense.

$\star \star \star$ Professor Adjunto do Curso de Psicologia - Universidade Federal Fluminense; Pós-doutoranda em Psiquiatria, IPUB/Universidade Federal do Rio de Janeiro; Doutora e Mestre em Psicologia, IP/Universidade Federal do Rio de Janeiro. E-mail: adrianacardosorj@yahoo.com.br
} 
